\title{
Laser Peening- Strengthening Metals to Improve Fatigue Lifetime and Retard Stress-Induced Corrosion Cracking in Gears, Bolts and Cutters
}

\section{Hackel, H-L. Chen}

U.S. Department of Energy

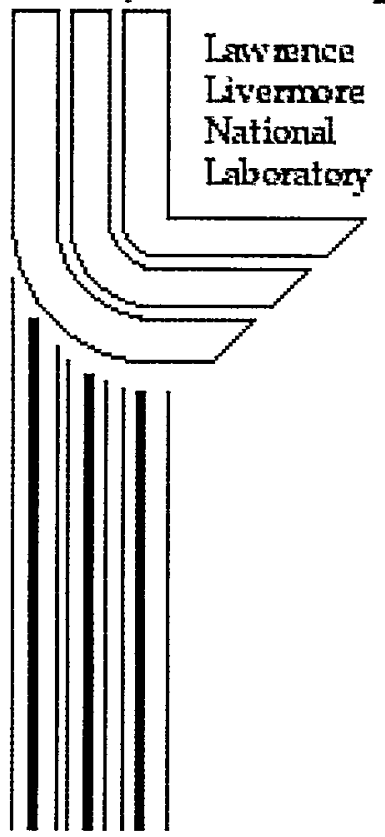

August 20, 2003 
This document was prepared as an account of work sponsored by an agency of the United States Government. Neither the United States Government nor the University of California nor any of their employees, makes any warranty, express or implied, or assumes any legal liability or responsibility for the accuracy, completeness, or usefulness of any information, apparatus, product, or process disclosed, or represents that its use would not infringe privately owned rights. Reference herein to any specific commercial product, process, or service by trade name, trademark, manufacturer, or otherwise, does not necessarily constitute or imply its endorsement, recommendation, or favoring by the United States Government or the University of California. The views and opinions of authors expressed herein do not necessarily state or reflect those of the United States Government or the University of California, and shall not be used for advertising or product endorsement purposes.

This work was performed under the auspices of the U.S. Department of Energy by University of California, Lawrence Livermore National Laboratory under Contract W7405-Eng-48. 


\section{Laser Peening-Strengthening Metals to Improve Fatigue Lifetime and Retard Stress-Induced Corrosion Cracking in Gears, Bolts and Cutters}

By Lloyd Hackel and Hao-Lin Chen, Lawrence Livermore National Laboratory, Livermore, California 92551

Laser peening is an emerging modern process that impresses a compressive stress into the surfaces of metals. Treatment can reduce the rate of fatigue cracking and stress-corrosion-cracking in metals (such as gears, bolts and cutters) needed for tunnel boring and other construction \& mining applications. Laser peening could also be used to form metals or alloys into a precise shape without yielding and leaving both surfaces in a crack resistant compressive state.

When metal is bent, the surface of the outer radius is stretched into a tensile state. Under tension, any flaw or microcrack will grow in size with each flexure until the crack spreads through the entire strip, breaking it into two pieces. Flexure of metal components occurs in most applications. The process of metal forming and welding can also cause tensile stress that allows defects to grow into cracks and accelerate corrosion. If fatigue or stress-corrosion-cracking failures from load or vibration occurs in the underground excavation equipment such as bolts, gears and cutter rings used for tunnel boring, significant loss of assets, service life and potential loss of business can occur.

Laser peening, better than any other technique, has been proven to extend the fatigue and stress-corrosion-cracking lifetimes of metal components. Laser peening of root area of gears increases bending fatigue strength and lifetime for high cycle fatigue. Recent testing has also demonstrated significantly improvement in highstress component lifetimes; 2-to-6X in automotive and helicopter gears and up to $10 \mathrm{X}$ in bearing lifetime after laser treatment. Although, we have not performed any peening and fatigue experiments on the underground excavation equipment, improvement in both fatigue and stress-corrosion-cracking lifetimes are anticipated.

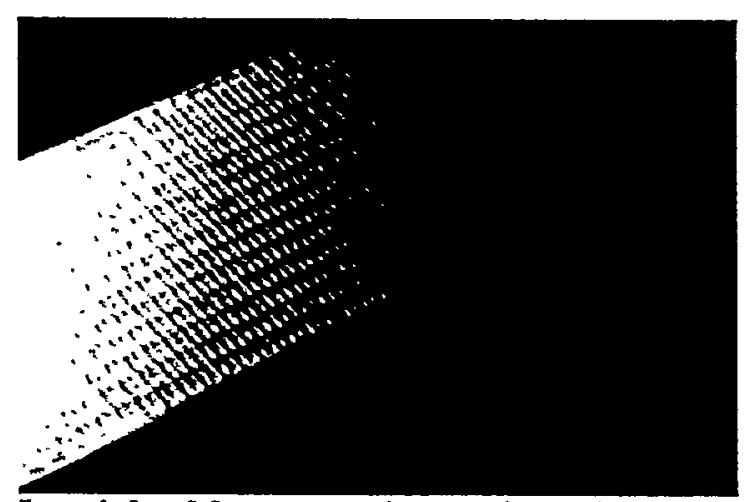

Leser-induced deep compressive stress in metal.
In the laser peening process a high energy laser beam creates an intense pressure wave (of about 1 million pounds per square inch) on the surface of the metal, straining the metal and leaving a residual compressive stress both on and several $\mathrm{mm}$ inside of the metal surface. If the compressive stress is intense and deep enough, when the component flexes under a load, the surface remains in compression, and a microcrack or flaw on the surface cannot grow.

Tests on structural aluminum components, under heavy load are showing 10 to 15 times lifetime improvements. As shown in the figure below, recent fatigue tests on $6061 \mathrm{~T} 6$ aluminum under various stress load conditions show more than 50 times improvement in fatigue lifetime for structural aluminum test plates when compared to unpeened components and 10 times improvement when compared to conventionally shot-peened components.

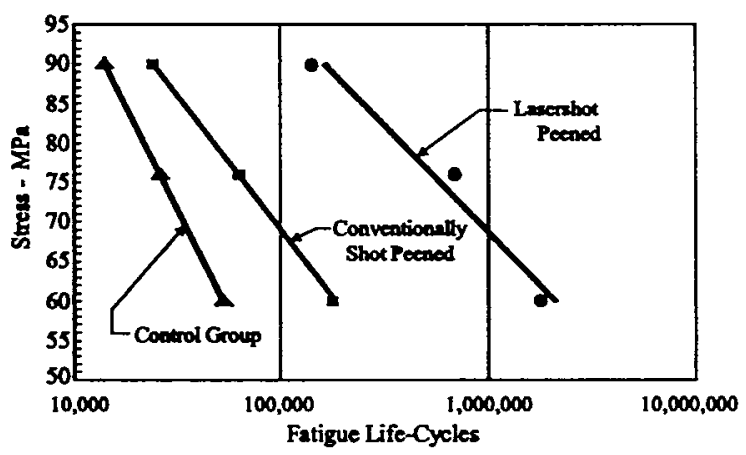

Comparison of fatigue tests on aluminum under various stress lond conditions.

Recent experiments at LLNL have also shown that laser peening can virtually eliminate occurrence of stress corrosion cracking in metal. During an accelerated stress-corrosion cracking experiment in an aqueous solution of $\mathrm{MgCl}_{2}$ at high temperature, we measured the lifetime of 304 stainless steel under high stress conditions. The unpeened U-bends broke into two pieces within 2 hours, while the laser-peened U-bends showed no signs of cracking after more 6 days. (see photo on next page) 


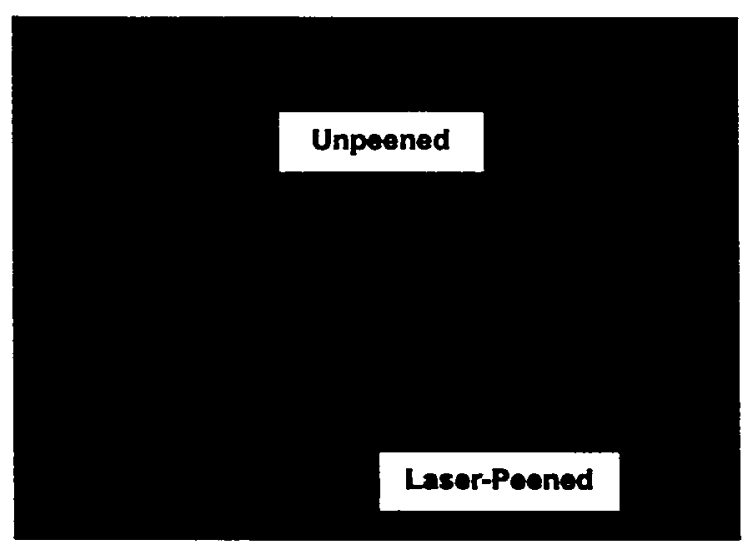

Peened U-bend shows no sign of cracking.

This compressive residual stress, selectively induced by the laser, can also be used to cause the metal to curve in a precisely controlled fashion. Now for the first time, metal up to 1 inch thick can be formed to tight radii and to difficult contours.

The concept of laser peening has been known for over 20 years. However, a highenergy laser suitable for production processing has not existed. Within the last several years, using knowledge gained from Department of Energy (DOE)-funded laser fusion work and from contracts for Department of Defense projects, Lawrence Livermore National Laboratory has developed a high-energy laser peening system with an average power 20 times higher than any other available technology.

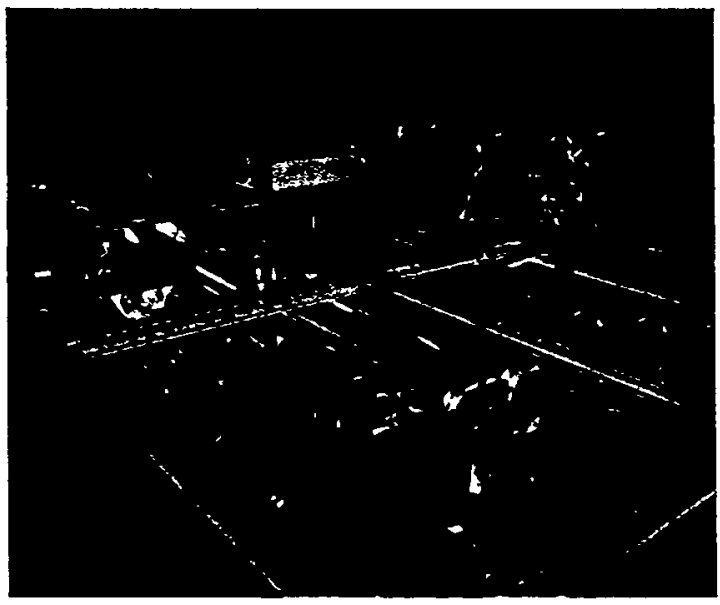

LLNL's haser peening system.

\section{Laser Peening is a Developed Process -Enhancing Fatigue Lifetime and System Safety}

Laser peening was introduced into commercial production by Metal Improvement Company, (our Cooperative Research and Development Agreement partner) in May 2002. This peening system was deployed to solve an important fatigue failure problem in high-value commercial jet engine fan blades and discs. Since initial deployment, multiple applications and aircraft worth billions of dollars are now in service with laser-peened parts--saving millions of dollars per month in aircraft maintenance costs, millions more in parts replacement costs and all the while greatly enhancing safety.

Laser peening is already having an important impact in preventing the failure of jet engine fan blades. The high-stress and high-cycle loading of these components has led to failures. Led initially by the U.S. Air Force, research showed that laser treatment of the leading edge of blades against foreign object debris damage significantly extends the fatigue lifetime and allows even a highly damaged but laser-peened blade to have better fatigue lifetime than unpeened new blade. An even greater magnitude application has been the treatment of wide cord fan blades for commercial engines to prevent fretting fatigue failure.

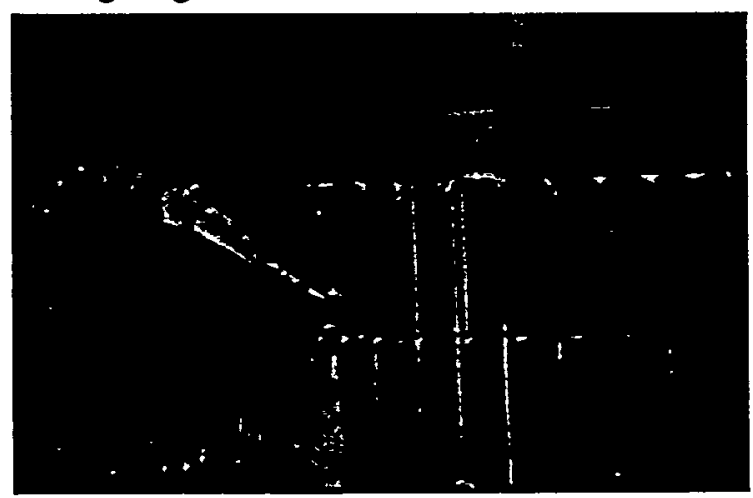

Laser peening increases bending fatigue strength

The hard rock tunnel boring industry can now apply the laser peening technology to reduce the rate of fatigue cracking and stresscorrosion-cracking in gears, bolts and cutters used for tunnel boring and other construction \& mining application. This will significantly extend the operational life of the next generation TBM so that they will have higher boring speed and lower operating cost.

We are available to work with Herrenknecht and other interested users to optimize process parameters and develop processing tools for their specific applications.

\section{If interested please contact:}

\section{Lloyd A. Hackel}

Phone: (925) 422-9009

Email:hackel1 @llnl.gov

or

Hao-Lin Chen

Phone: (925) 422-6198

Email: chen4@llnl.gov 